\title{
PENGARUH SISTEM INFORMASI MANAJEMEN TERHADAP KINERJA KARYAWAN PADA PT. PRIMANUSA GLOBALINDO PEKANBARU
}

\author{
Jeli Nata Liyas ${ }^{1}$, Ferisca Nur Widyanti ${ }^{2)}$ \\ Sekolah Tinggi Ilmu Ekonomi Riau \\ jaznatan@yahoo.co.id
}

\begin{abstract}
The purpose of this study was to determine the effect of management information systems on employee performance at PT. Primanusa Globalindo Pekanbaru. The sample of this study were employees who worked at PT. Primanusa Globalindo Pekanbaru. Data collection was carried out with questionnaires distributed directly to employees totaling 54 questionnaires. Statistical methods using Simple Linear Regression Analysis with hypothesis testing statistical tests $t$. From the overall response of respondents to the variable management information system at PT. Primanusa Globalindo Pekanbaru with an average score of 4.61 shows the response of respondents to the statement on the management information system variable is very agree. From the overall response of respondents to the variable employee performance at PT. Primanusa Globalindo Pekanbaru with an average score of 4.38 shows the response of respondents to statements on employee performance variables is agreed. T value of 4.048. While the critical value according to the table with a significant level of 5\% using the formula t table $(\alpha / 2 ; n-k) k=1$ and $n=54$ is 2.00575 , because $t$ arithmetic $>t$ table then Ho is rejected. This means that the Management Information System has a positive effect on Employee Performance. With the meaning of the word Hypothesis ( Ha) accepted. Positive t value indicates that the Management Information System variable has a direct relationship with Employee Performance at PT. Primanusa Globalindo Pekanbaru.
\end{abstract}

Keywords: Management Information Systems, Employee Performance

\begin{abstract}
Abstrak
Tujuan dari penelitian ini adalah untuk mengetahui pengaruh sistem informasi manajemen terhadap kinerja karyawan di PT. Primanusa Globalindo Pekanbaru. Sampel penelitian ini adalah karyawan yang bekerja di PT. Primanusa Globalindo Pekanbaru. Pengumpulan data dilakukan dengan kuesioner yang dibagikan langsung ke karyawan berjumlah 54 kuesioner. Metode statistik menggunakan Analisis Regresi Linier Sederhana dengan uji statistik uji hipotesis t. Dari tanggapan responden secara keseluruhan terhadap sistem informasi manajemen variabel di PT. Primanusa Globalindo Pekanbaru dengan skor rata-rata 4,61 menunjukkan tanggapan responden terhadap pernyataan tentang variabel sistem informasi manajemen sangat setuju. Dari keseluruhan tanggapan responden terhadap variabel kinerja karyawan di PT. Primanusa Globalindo Pekanbaru dengan skor rata-rata 4,38 menunjukkan tanggapan responden terhadap pernyataan tentang variabel kinerja karyawan disepakati. Nilai T sebesar 4,048. Sedangkan nilai kritis menurut tabel dengan taraf signifikan 5\% menggunakan rumus $\mathrm{t}$ tabel $(\alpha / 2 ; \mathrm{n}-\mathrm{k}) \mathrm{k}=1$ dan $\mathrm{n}=54$ adalah 2,00575, karena t hitung $>t$ tabel maka Ho ditolak. Ini berarti bahwa Sistem Informasi Manajemen memiliki efek positif pada Kinerja Karyawan. Dengan makna kata Hipotesis (Ha) diterima. Nilai t positif menunjukkan bahwa variabel Sistem Informasi Manajemen memiliki hubungan langsung dengan Kinerja Karyawan di PT. Primanusa Globalindo Pekanbaru.
\end{abstract}

Kata Kunci: Sistem Informasi Manajemen, Kinerja Karyawan 


\section{PENDAHULUAN}

Sistem informasi secara sederhana banyak membantu kalangan perusahaan di dalam mendapatkan informasi mengenai bisnis perusahaan. Sementara perkembangan sistem informasi yang berbasis komputer membutuhkan sumber daya untuk menganalisis dan merancang sistem dan dapat menghabiskan waktu yang banyak untuk dapat menyelesaikannya. Terkadang sistem yang dikembangkan dan dibuat sesuai rencana mengalami kendala-kendala yang tidak dapat diatasi maka diperlukan kebijakan pengembangan sistem agar dapat mengatasinya. Menurut Nurmansyah (2018:27), menjelaskan dalam bukunya bahwa Informasi merupakan hal yang sangat penting bagi suatu perusahaan dalam menentukan keunggulan bersaing dan memenangkan dalam persaingan. Karena hal tersebut, maka informasi harus dilihat sebagai aset yang sangat berharga. Informasi adalah modal intelektual (intellectual capital) yang mempunyai pengaruh penting dalam menentukan daya saing suatu perusahaan dalam jangka panjang. Sedangkan pengertian sistem informasi manajemen menurut Scott (2002) dalam buku Nurmansyah (2018:133) menyatakan bahwa, Sistem informasi manajemen adalah serangkaian sub-sistem informasi yang menyeluruh dan terkoordinasi secara rasional terpadu yang mampu mentransformasikan data sehingga menjadi informasi yang melalui serangkaian cara guna meningkatkan produktivitas yang sesuai dengan gaya dan sifat manajer atas dasar kriteria mutu yang telah ditetapkan.

Sistem informasi yang menyajikan banyak hal tentang bisnis perusahaan perlu diimbangi dengan pengetahuan tentang kinerja karyawan, yang semua ini diharapkan dapat dilakukan oleh para karyawan yang bekerja dalam perusahaan. Terkadang banyak terdapat ketidakpahaman para karyawan terhadap sistem informasi yang berlaku dalam perusahaan. Ketidakmengertian akan proses-proses yang berlaku dan terjadi dalam perusahaan sebaiknya tidak menjadi alasan untuk perusahaan lebih memperhatikan karyawan sebaik mungkin. Karena peningkatan pendapatan perusahaan tidak bisa dilepaskan dari pemahaman karyawan akan sistem informasi yang digunakan perusahaan. PT. Primanusa Globalindo merupakan sebuah perusahaan yang bergerak di bidang Kontraktor dan Supplier. PT. Primanusa Globalindo merupakan Authorizer Distributor Vehicle Safety atau Drive Behavior Monitoring System (DBMS) Di Indonesia. PT. Primanusa Globalindo berdiri sejak tahun 2002 yang dipimpin oleh Bapak Sunarto. Pada mulanya perusahaan ini masih berbentuk CV. Primanusa, kemudian dengan seiring berkembangnya waktu maka perusahaan ini kemudian berubah menjadi PT. Primanusa Globalindo, yang mana ruang lingkup usahanya usahanya, meliputi daerah Duri, Minas, Palembang, Jakarta.

PT. Primanusa Globalindo merupakan sole distributor resmi dari product Driver Behaviour Monitoring System (DBMS) merk Driveright dengan principle di USA. Product tersebut dipakai bukan hanya di Indonesia tetapi di seluruh dunia dan telah terbukti berhasil membantu para fleet manager dalam hal manajemen armada dan khususnya memperbaiki behavior dari para driver. Setelah sukses dengan pemasaran Drive Right, PT. Primanusa Globalindo kemudian menjadi sole distributor product GPS (Global Positioning System) tracking dari negara yang sudah terkenal akan kecanggihan teknologinya, yaitu Taiwan.

Gtrack, merek GPS tracking yang sudah tidak asing lagi bagi kita saat ini menjadi market leader di niche marketnya yaitu perusahaanperusahaan perminyakan dan gas. PT. Primanusa Globalindo terus melakukan expansi market sehingga Gtrack sekarang juga sangat dikenal di perusahaan pertambangan, logistic, rental, pharmacy dan sebagainya. 
Berikut Data Keadaan Karyawan yang Dilihat Dari Jumlah Karyawan Pada PT. Primanusa Globalindo Pekanbaru.

Tabel 1. Rekap Karyawan/Karyawati PT. Primanusa Globalindo Pekanbaru

\begin{tabular}{ccc}
\hline No & Tahun & Jumlah Karyawan (Orang) \\
\hline 1 & 2014 & 28 \\
2 & 2015 & 33 \\
3 & 2016 & 36 \\
4 & 2017 & 41 \\
5 & 2018 & 55 \\
\hline
\end{tabular}

Sumber : PT. Primanusa Globalindo Pekanbaru 2019

Dari tabel di atas dapat dilihat bahwa perkembangan karyawan yang ada di PT. Primanusa Globalindo Pekanbaru dari tahun ke tahun meningkat. Di tahun 2014. Karyawan yang ada di perusahaan ini hanya 28 orang, meningkat di tahun berikutnya menjadi 33 orang, lalu di bulan berikutnya menjadi 36 orang, di tahun berikutnya lagi 41 orang. Dan pada tahun 2018 karyawan PT. Primanusa Globalindo Pekanbaru menjadi 55 orang. Di sini dapat dilihat adanya peningkatan jumlah karyawan dari tahun ke tahun.

Tabel 2. Tingkat Pendidikan Karyawan/Karyawati PT. Primanusa Globalindo Pekanbaru

\begin{tabular}{clcc}
\hline No & \multicolumn{1}{c}{ Tingkat Pendidikan } & Jumlah (orang) & Persen (\%) \\
\hline 1 & Pasca Sarjana & - & - \\
2 & Sarjana (S1) & 37 & $67,3 \%$ \\
3 & DIV & 9 & $16,3 \%$ \\
4 & DIII & 2 & $3,63 \%$ \\
5 & SMA / Sederajat & 7 & $12,7 \%$ \\
& \multicolumn{1}{c}{ Jumlah } & $\mathbf{5 5}$ & $\mathbf{1 0 0}$ \\
\hline
\end{tabular}

Sumber : PT. Primanusa Globalindo Pekanbaru 2019

Dari tabel di atas dapat dilihat tingkat pendidikan karyawan PT. Primanusa Globalindo Pekanbaru lebih didominasi pada tingkatan S1, yaitu sebanyak 37 orang 67,3\%, pada tingkatan DIV sebanyak 9 orang atau 16,3, pada tingkatan DIII sebanyak 2 orang atau 3,63\%, dan yang berpendidikan SMA sederajat sebanyak 6 orang atau $12,7 \%$.

\section{Manfaat dan Type GPS Pelacak} Kendaraan Pada PT. Primanusa Globalindo Pekanbaru

Semakin berkembangnya teknologi komunikasi menjadikan berbagai alat- alat telekomunikasi semakin canggih. Dari pada awalnya hanya sebuah pengirim pesan dengan nada morse kemudian tulisan, suara, hingga pada akhirnya sebuah sinyal yang tidak terlihat kasat mata. Penggunaan alat telekomunikasi pun semakin berkembang, tidak hanya antara dua orang tetapi juga dengan banyak orang dengan berbagai kemampuan dan kebutuhan masing-masing, baik dari sisi penyedia atau pun dari sisi pengguna itu sendiri.

Fungsi ini hampir sama dengan navigasi, jika dalam navigasi mengguna- 
kan perangkat penerima sinyal GPS berikut penampil titik koordinatnya dalam satu perangkat, sedangkan untuk kebutuhan sistem pelacakan adalah alat penampil dan penerima sinyal berbeda lokasi. Contohnya kita bisa mengetahui lokasi kendaraan yang hilang dengan melihat titik kordinat yang dihasilkan dari alat yang terpasang dalam kendaraan tersebut, untuk melihatnya bisa melalui media smartphone atau alat khusus lainnya.

\section{Type GPS dan fungsinya sebagai berikut:}

a. U1 plus $2 \mathrm{G} / 3 \mathrm{G}$ adalah alat tracking sistem yang bertujuan untuk program fleet management sistem. Dengan teknologi pemantauan dan pengamanan terhadap aset kendaraan yang menyajikan data realtime, sehingga monitoring kendaraan Anda bisa diketahui keberadaan dan pergerakan bahkan bisa melihat histori perjalanan sebelumnya.

\section{Advantages :}

1. Realtime monitoring menggunakan fleetweb ataupun aplikasi smartphone.

2. Matikan kendaraan dari jarak jauh.

3. Memantau dan Memproteksi pencurian bahan bakar.

4. Mengetahui perilaku pengemudi.

5. Terdapat record data detail per detik sebelum dan sesudah terjadi benturan.

\section{Available Features :}

1. Door Sensor

2. SOS Button

3. Seat Belt Trigger

4. Buzzer Speed

5. Fatigue Sensor

6. Fuel Monitor

7. Smoke Detector

8. Unloading Sensor

9. Barcode Scanner

10. Geofence Implementation

11. Buzzer Idle

12. Work Hour b. U1 plus $3 \mathrm{G}$ Camera adalah alat tracking sistem yang bertujuan untuk program fleet management sistem. Dengan teknologi pemantauan dan pengamanan terhadap aset kendaraan yang menyajikan data realtime, sehingga monitoring kendaraan Anda bisa diketahui keberadaan dan pergerakan bahkan bisa melihat histori perjalanan sebelumnya. Unit GPS Tracking ini dilengkapi dengan Camera Capture yang dapat diintegrasikan maksimal 4 kamera dan Jaringan 3G, maka hasil pantau kinerja kendaraan operasional Anda semakin maksimal :

\section{Advantages :}

1. Realtime monitoring menggunakan fleetweb ataupun aplikasi smartphone.

2. Matikan kendaraan dari jarak jauh.

3. Memantau dan Memproteksi pencurian bahan bakar.

4. Mengetahui perilaku pengemudi.

5. Terdapat record data detail per detik sebelum dan sesudah terjadi benturan.

\section{Available Features :}

1. Door Sensor

2. SOS Button

3. Seat Belt Trigger

4. Buzzer Speed

5. Fatigue Sensor

6. Fuel Monitoring

7. Smoke Detector

8. Unloading Sensor

9. Barcode Scanner

10 Geofence Implementation

11. Buzzer Idle

12. Work Hour

c. U1 Lite plus adalah alat tracking sistem yang bertujuan untuk program fleet management sistem. Dengan teknologi pemantauan dan pengamanan terhadap aset kendaraan yang menyajikan data realtime, sehingga monitoring kendaraan Anda bisa diketahui keberadaan dan pergerakan bahkan bisa melihat histori perjalanan sebelumnya. 


\section{Advantages :}

1. Realtime monitoring menggunakan fleetweb ataupun aplikasi smartphone.

2. Matikan kendaraan dari jarak jauh.

3. Memantau dan Memproteksi pencurian bahan bakar.

4. Mengetahui perilaku pengemudi.

5. Terdapat record data detail per detik sebelum dan sesudah terjadi benturan.

\section{Available Features :}

1. Door Sensor

2. SOS Button

3. Seat Belt Trigger

4. Buzzer Speed

5. Fuel Monitoring

6. Unloading Sensor

7. Geofence Implementation

8. Buzzer Idle

9. Work Hour

10. Driver Safety Score/ Driver Behavior

d. GPS UECO, seiring dengan meningkatnya kebutuhan customer akan teknologi GPS Tracking dengan harga terjangkau namun tetap dengan kualitas prima. GPS Tracker UECO hadir dalam memenuhi kebutuhan pemantauan kendaraan dengan fitur melimpah namun dengan harga ekonomis..

\section{Advantages :}

1. Realtime monitoring menggunakan fleetweb ataupun aplikasi smartphone.

2. Matikan kendaraan dari jarak jauh.

3. Mengetahui perilaku pengemudi (Driving Behavior).

\section{Available Features :}

1. Door Sensor

2. SOS Button

3. Seat Belt Trigger

4. Buzzer Speed

5. Unloading Sensor

6. Geofence Implementation

7. Buzzer Idle

8. Work Hour

9. Driver Safety Score/ Driver Behavior e. GT710 adalah GPS Tracking Portable tahan air yang dirancang untuk pelacakan kendaraan ataupun aset. Bebas pemasangan dan tahan lama. Dengan ditopang magnet yang sangat kuat dan bentuknya yang kecil sehingga mudah untuk disembunyikan.

\section{Advantages :}

1. Realtime / berkala monitoring menggunakan SMS, fleetweb ataupun aplikasi smartphone.

2. Baterai tahan lama selama 3 tahun dan ada notifikasi low battery \& shut down.

3. Unit waterproof dan dustproof.

4. Tersedia Alert ketika unit berpindah.

Available Features :

1. Standby Time 3 Tahun

2. Dustproof

3. Strong Magnetic Mounting

4. Notification Low Battrery

f. Human Tracking Dwatch adalah jam tangan yang dapat difungsikan untuk memantau personal, anak-anak ataupun manula beraktifitas. Dengan desain yang simpel dan trendi, Anda dapat menjaga dari bahaya yang mengancam, dan dapat melakukan percakapan dengan orang tercinta

\section{Advantages :}

1. Realtime monitoring menggunakan aplikasi smartphone.

2. Record histori perjalanan selama 3 bulan.

3. Dapat melakukan panggilan kedua nomor dengan menekan speed dial, dan panggilan ke nomor yang telah didaftarkan.

4. Tersedia tombol SOS.

5. Dapat menyadap suara sekitar unit Dwatch.

\section{Available Features :}

1. Geofence Implementation

2. Voice TalkBack

3. Whitelist Number Love Reward

4. Demolition Alaram

5. Remote Shutdown 


\section{Gambar 1. Cara Kerja GPS}

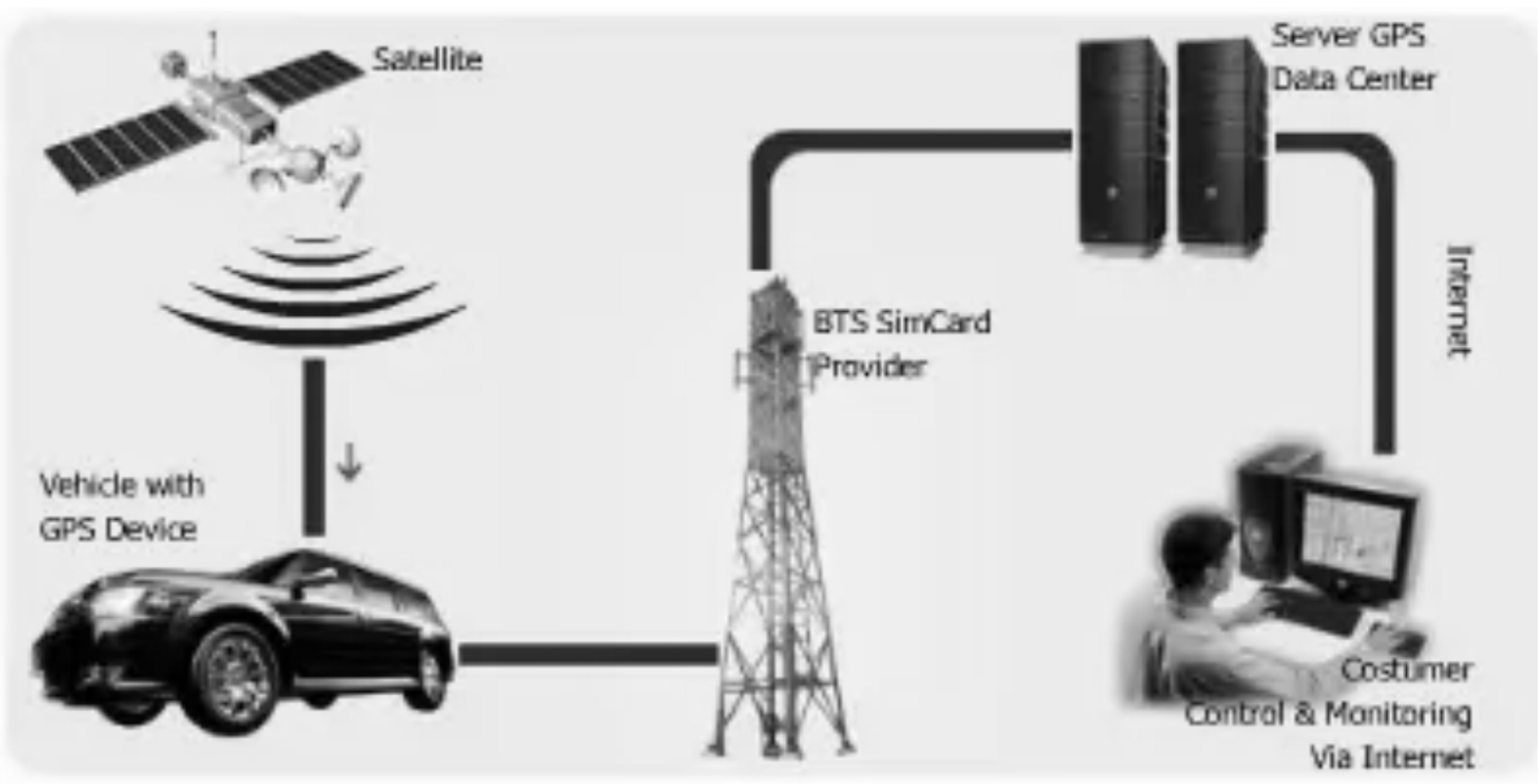

Tabel 3. Data yang menggambarkan Sistem Informasi Manajemen pada PT. Primanusa Globalindo Pekanbaru

\begin{tabular}{cccc}
\hline Tahun & $\begin{array}{c}\text { Data Job Report } \\
\text { (Unit) }\end{array}$ & Terjadi Kesalahan & Persentase (\%) \\
\hline 2014 & 3527 & 120 & $3,4 \%$ \\
2015 & 6500 & 93 & $1,43 \%$ \\
2016 & 3337 & 25 & $0,75 \%$ \\
2017 & 7120 & 54 & $0,76 \%$ \\
2018 & 5000 & 47 & $0,94 \%$ \\
\hline
\end{tabular}

Sumber : PT. Primanusa Globalindo Pekanbaru 2019

Pada tahun 2014 PT. Primanusa Globalindo Pekanbaru masih menerapkan penginputan data Job Report (JR) dengan cara manual, sehubungan dengan semakin pesatnya daya saing maka PT. Primanusa Globalindo Pekanbaru mencoba untuk menerapkan penginputan data Job Report (JR) dengan menerapkan sistem. Penerapan ini dimulai pada awal Mei 2015, dengan tujuan untuk mengetahui dengan cepat datadata yang diinputkan pada sistem seperti, penagihan unit GPS, pemasangan unit GPS, pelepasan unit GPS, aktifasi unit GPS dan hal-hal lain yang berhubungan dengan data GPS dan untuk memperkecil kesalahan. Namun seiringan dengan waktu ternyata dengan diterapkannya penginputan data melalui sistem maka Manajemen PT. Primanusa Globalindo memutuskan untuk penggunaan Rekap Job Report Online diterapkan sampai saat ini karena dinilai sangat efektif dan efisien.

Tetapi pada saat penginputan data dengan menggunakan sistem terdapat kendala pada sumber daya manusianya karena setiap orang memiliki pemahaman yang berbeda-beda, maka sebelum diterapkan penginputan data baru, yang disebut dengan sistem tersebut diperlukan adanya pelatihan kepada setiap karyawan agar setiap individu dapat memahami dan meningkatkan kinerjanya. Selain dengan diperlukannya pelatihan 
maka juga diperlukannya kerjasama pada setiap karyawan untuk mempermudah dan mempercepat pengetahuan pada setiap karyawan untuk menggunakan sistem online.

Dengan penerapan sistem informasi manajemen diharapkan dapat mempermudah pekerjaan karena informasi yang didapat mempunyai manfaat untuk pemakainya, informasi tersebut juga datang pada penerima tidak boleh terlambat karena jika informasi datang pada penerima lambat maka akan berdampak pada kualitas perusahaan, informasi juga harus bebas dari kesalahan diharapkan dengan adanya sistem informasi manajemen ini dapat meminimalisir kesalahan pemberian informasi baik dari internal perusahaan mau pun eksternal perusahaan. Dengan begitu manajemen perusahaan harus selalu memberikan pelatihan kepada setiap karyawan agar sistem yang telah dibuat dan diterapkan pada manajemen dapat berjalan sesuai dengan kebutuhan.

Tabel 4. Data Jenis kesalahan pada saat penginputan Job Report PT. Primanusa Globalindo Pekanbaru

\begin{tabular}{cll}
\hline No & Jenis Kesalahan & \multicolumn{1}{c}{ Keterangan } \\
\hline 1 & Data Unit GPS & Unit ID, Serial Number, Imei \\
2 & Data Kendaraan & Nomor Polisi dan Nomor Dinding \\
3 & Data GSM & Nomor GSM \\
& & RFID, Camera, Fuel Stick, Sensor pintu, SOS, Bypass \\
4 & Data Asesoris & dan lainnya \\
5 & Data Tanggal & Tanggal Pemasangan, Nonaktif dan Dismantle \\
\hline
\end{tabular}

Sumber : PT. Primanusa Globalindo Pekanbaru 2019

Dari tabel di atas dapat dilihat ada beberapa jenis kesalahan yang sering terjadi pada saat penginputan Job Report yang diinputkan oleh teknisi dan keterangannya, hal ini yang harus diminimalisir agar memberikan kemudahan kepada user serta memberikan infomasi yang relevan dan akurat sehingga informasi yang didapat juga bisa tepat waktu.

Tabel 5. Data Target dan Capaian Kerja Karyawan PT. Primanusa Globalindo Pekanbaru

\begin{tabular}{cccc}
\hline Tahun & Target $($ Unit $)$ & Realisasi (Unit) & Persentase $(\%)$ \\
\hline 2014 & 3000 & 3323 & $110 \%$ \\
2015 & 3500 & 6250 & $178 \%$ \\
2016 & 4000 & 2904 & $72,6 \%$ \\
2017 & 4500 & 7007 & $156 \%$ \\
2018 & 5000 & 4791 & $95,9 \%$ \\
\hline
\end{tabular}

Sumber : PT. Primanusa Globalindo Pekanbaru 2019

Dari tabel di atas dapat dilihat bahwa pencapaian kerja karyawan PT. Primanusa Globalindo Pekanbaru sudah cukup bagus. Hal ini dapat dilihat dari jumlah target yang telah ditentukan perusahaan pada tahun 2014 target penjualan 3000 unit dengan pencapaian 3323 unit atau naik sebanyak $110 \%$, hal ini juga terlihat pada tahun 2015 yang mana target penjualan sebanyak 3500 unit dengan pencapaian 6250 unit atau naik sebesar $178 \%$, 
pada tahun 2016 yang mana target penjualan sebanyak 4000 unit dengan pencapaian 2904 unit atau turun menjadi $72,6 \%$. Kemudian pada tahun 2017 target penjualan 4500 unit dengan pencapaian 7007 unit atau naik sebesar 156\%, dan pada tahun 2018 target penjualan sebanyak 5000 unit dengan pencapaian 4791 unit atau turun sebesar 95,9\%.

Berdasarkan latar belakang tersebut, maka penulis tertarik untuk meneliti tentang "Pengaruh sistem informasi manajemen terhadap kinerja karyawan pada PT. Primanusa Globalindo Pekanbaru”.

\section{Sistem Informasi Manajemen}

Sistem informasi manajemen mencerminkan suatu sikap para eksekutif yang menginginkan agar komputer tersedia untuk semua pemecah masalah perusahaan. Ketika sistem informasi manajemen (SIM) berada pada tempatnya dan berfungsi seperti yang diinginkan, manajemen dapat membantu manajer dan pemakaian lain di dalam dan di luar perusahaan dalam memahami masalahnya. Di dalam buku Nurmansyah (2018:133) terdapat beberapa definisi sistem informasi manajemen menurut para ahli di antaranya adalah sebagai berikut :

Menurut Gordon B. Davis (1985) di dalam buku Nurmansyah (2018:133) menyatakan bahwa "Sistem Informasi Manajemen sebagai seperangkat unsur-unsur yang terdiri dari manusia, alat, konsep dan prosedur yang dihimpun menjadi satu untuk maksud dan tujuan bersama". Selain itu Gordon B. Davis juga menyatakan bahwa Sistem Informasi Manajemen adalah sistem manusia dan mesin yang terintegrasi untuk menyajikan informasi dalam mendukung operasi, manajemen, dan pengambilan keputusan dalam suatu organisasi.

Menurut James A. F. Stoner (1995) di dalam buku Nurmansyah (2018:134) menyatakan bahwa Sistem Informasi
Manajemen adalah metode yang formal yang menyediakan bagi pihak manajemen suatu informasi yang tepat waktu, dapat dipercaya, untuk mendukung proses pengambilan keputusan bagi perencanaan, pengawasan dan fungsi operasi organisasi agar lebih efektif.

Menurut Murdick, Ross, dan Clugget (1997) di dalam buku Nurmansyah (2018:134) menyatakan bahwa Sistem Informasi Manajemen adalah kelompok orang, seperangkat pedoman dan petunjuk, peralatan pengolahan data yang digunakan untuk mengurangi ketidakpastian pada pengambilan keputusan dengan menghasilkan efisiensi untuk manajer pada waktu mereka dapat menggunakannya dengan efisien.

Menurut Schermerhorn, Jr (1999) di dalam buku Nurmansyah (2018:134) menyatakan bahwa: a management information system uses information technology to meet the information needs of managers as they make decisions (Sistem informasi manajemen adalah penggunaan teknologi informasi untuk memenuhi kebutuhan informasi bagi manajer sebagai pembuat keputusan).

Menurut Boone \& Krutz (2001) di dalam buku Nurmansyah (2018:134) menyatakan bahwa Sistem Informasi Manajemen adalah metode terintegrasi bagi penyediaan informasi-informasi masa lalu, masa sekarang, dan masa yang akan datang yang menyangkut tentang operasi-operasi internal serta intelijen eksternal dalam rangka mendukung proses pembuatan keputusan.

Menurut McLeod, Jr \& George P. Schell (2004) di dalam buku Nurmansyah (2018:134) menyatakan bahwa Sistem Informasi Manajemen adalah suatu sistem berbasis komputer yang membuat informasi tersedia bagi para pengguna yang memiliki kebutuhan serupa. 


\section{Kinerja Karyawan}

Menurut Barry (2002) dalam jurnal Abdul Hakim dan Wuryanto (2014:6) Kinerja adalah menilai bagaimana seseorang telah bekerja dibandingkan dengan target yang telah ditentukan. Rivai (2004) dalam jurnal Abdul Hakim dan Wuryanto (2014:06) mengemukakan kinerja adalah merupakan perilaku yang nyata yang ditampilkan setiap orang sebagai prestasi kerja yang dihasilkan oleh karyawan sesuai dengan perannya dalam perusahaan. Menurut Mathis and Jackson (2001) dalam jurnal Abdul Hakim dan Wuryanto (2014:06) menyatakan bahwa kinerja pada dasarnya adalah apa yang dilakukan atau tidak dilakukan karyawan.

Berdasarkan uraian tersebut dapat dijelaskan bahwa dengan hasil kinerja yang dicapai oleh seorang karyawan dalam melakukan suatu pekerjaan dapat dievaluasi tingkat kinerjanya, sehingga kinerja karyawan dapat ditentukan dengan pencapaian target selama periode waktu yang dicapai. Melalui pemahaman pekerjaan, seorang karyawan dapat diketahui berbakat dalam bidang tugasnya tertentu dan sanggup menyelesaikan pada jangka waktu yang ditetapkan. Jadi apa yang telah dipahami dengan benar tentang pekerjaan yang telah dibebankan akan membawa manfaat bagi pegawai, mendukung kelangsungan pekerjaan dan digunakan sebagai pengukuran hasil kerjanya.

Faktor yang mempengaruhi kinerja dari individu tenaga kerja di antaranya, skill, motivasi, disiplin kerja, keberadaan pekerjaan yang mereka lakukan, imbalan atau intensif, hubungan mereka dengan organisasi dan masih banyak lagi faktor-faktor lainnya. Kinerja Karyawan baik di perusahaan maupun di pemerintahan memerlukan adanya suatu pengawasan. Pengawasan dengan kata lain merupakan suatu penilaian kinerja karyawan. Penilaian kinerja sangat bermanfaat bagi organisasi dan untuk kemajuan Karyawan itu sendiri. Pengertian penilaian kinerja karyawan dikemukakan oleh Mangkunegara (2007:10) yaitu: "Penilaian prestasi kerja (Performance apparaissal) adalah suatu proses yang digunakan pemimpin untuk menentukan apakah seorang Karyawan melakukan pekerjaannya sesuai dengan tugas dan tanggungjawabnya”.

Berdasarkan definisi di atas, penilaian kinerja Karyawan menurut Mangkunegara merupakan hal yang dilakukan pimpinan untuk menerapkan disiplin kepada Karyawan. Penerapan disiplin dimaksudkan supaya karyawan bertanggung jawab atas pekerjaan. Peneliti berpendapat, bahwa penilaian kinerja sangat baik untuk dilakukan dan merupakan suatu keharusan untuk perbaikan kinerja karyawan. Apabila suatu organisasi khususnya di pemerintahan tidak melakukan penilaian kinerja, maka bisa terjadi adanya kekacauan dan kerugian. Penggunaan penilaian kinerja Karyawan juga memiliki kelebihan dan kekurangan tersendiri. Penilaian kinerja menuntut seorang pemimpin dan Karyawan harus kerja sama dengan tujuan utama sebagai patokan.

Menurut Flipo (1984:14) dalam jurnal Suyitno (2017:126) menyatakan bahwa "seseorang agar tercapai kinerja yang tinggi tergantung pada kerjasama, kepribadian, kepandaian yang beraneka ragam, kepemimpinan,. Keselamatan, pengetahuan pekerjaan, kehadiran kesetiaan, ketangguhan dan inisiatif'. Kerjasama antar pegawai yang ada di organisasi tersebut dalam rangka melaksanakan tugas dan pekerjaannya, baik kerjasama antar atasan dan bawahan maupun kerjasama antar bawahan. Kepribadian antar pegawai menentukan baik buruknya hasil kerja. Kinerja pegawai dipengaruhi oleh kerjasama, kepribadian yang beraneka ragam, kepemimpinan, keselamatan, pengetahuan pekerjaan, kehadiran, kesetiaan, ketangguhan dan inisiatif produktifitas sangat perlu mendapatkan perhatian dari pihak manajemen organisasi. 


\section{METODE PENELITIAN}

\section{Populasi}

Populasi dalam penelitian ini adalah karyawan PT. Primanusa Globalindo yang berjumlah 55 orang.

\section{Sampel}

Menurut Sugiono (2003:78) sampling jenuh adalah teknik penentuan sampel bila semua anggota populasi digunakan sebagai sampel. Jadi sampel dalam penelitian ini adalah 54 orang.

\section{Metode Analisis Data}

Analisis data dapat diartikan sebagai upaya data yang sudah tersedia kemudian diolah dengan statistik dan dapat digunakan untuk menjawab rumusan masalah dalam penelitian Sujarweni (2014:103).nPenulis menggunakan analisis kuantitatif yaitu :

\section{a. Uji Validitas}

Menurut Arikunto (2010:211), Validitas adalah suatu ukuran yang menunjukkan tingkat-tingkat kevalidan atau kesahihan sesuatu instrumen. Jika instrumen itu valid, maka cerita yang digunakan atau batas minimum suatu instrumen atau bahan tes dinyatakan valid, jika harga koefisien rhitung $>$ r tabel.

\section{b. Uji Reliabilitas}

Menurut Arikunto (2010:221), Reliabilitas menunjukkan pada satu pengertian bahwa sesuatu instrumen cukup dapat dipercaya untuk digunakan sebagai alat pengumpulan data karena instrumen tersebut sudah baik. Tingkat reliabilitas suatu item dapat dilihat dari hasil uji statistic Cronbach Alpha. Suatu konstruk dikatakan reliabel jika memberikan nilai Cronbach Alpha $>0,60$ (Ghozali, 2006:32).

\section{c. Uji Normalitas}

Menurut Ghozali (2011:160) uji normalitas berfungsi untuk menguji apakah sebuah model regresi, variabel pengganggu memiliki distribusi normal dalam penelitian ini akan digunakan dengan menggunakan taraf signifikansi 0,05. Data dinyatakan berdistribusi normal jika signifikansi lebih besar dari 0,05.

\section{d. Regresi Linier Sederhana}

Menurut Sudjana (2006:356) dalam jurnal Adhityo Kuncoro (2017:307) regresi dibagi menjadi dua, yaitu analisis linier sederhana dan analisis linier berganda. Analisis regresi linier adalah jika hubungan persamaan antar variabel bebas (X) dan variabel $(\mathrm{Y})$ searah dan membentuk sebuah pola garis lurus. Jadi, jika nilai variabel (X) meningkat, maka nilai variabel (Y) juga meningkat. Begitu pula sebaliknya, jika antara (X) dan (Y) mengalami hubungan negatif. Berikut adalah rumusan dari regresi linier:

$$
\mathbf{Y}=\mathbf{a}+\mathbf{b X}
$$

Keterangan:

$\mathrm{Y}=$ Kinerja, yaitu subjek dalam variabel dependen (tidak bebas) yang diprediksikan.

$\mathrm{X}=$ Sistem Informasi Manajemen, yaitu subjek pada variabel independen (bebas) yang mempunyai nilai tertentu.

$\mathrm{a}=$ Parameter intercept.

$\mathrm{b}=$ Parameter koefisien regresi variabel bebas.

\section{e. Ujit}

Uji t yaitu untuk mengetahui signifikasi dari pengaruh variabel independen terhadap variabel dependen secara individual dan menganggap dependen yang lain konstan. Signifikasi pengaruh tersebut dapat diestimasi dengan membandingkan antara nilai $t$ tabel dengan nilai t hitung. Apabila nilai t hitung lebih besar daripada $\mathrm{t}$ tabel maka variabel independen secara individual mempengaruhi variabel dependen. Sebaliknya jika nilai t hitung lebih kecil daripada t tabel maka variabel independen secara individual tidak mempengaruhi variabel dependen (Supranto, 2009:335). 


\section{f. Koefisien Determinasi $\left(R^{2}\right)$}

Koefisien Determinasi adalah salah satu nilai statistik yang dapat digunakan untuk mengetahui apakah antara dua variabel. Nilai koefisien determinasi yang biasanya diberi simbol $\mathrm{R}^{2}$ menunjukkan hubungan pengaruh dua variabel yaitu variabel independen dan variabel dependen dari hasil perhitungan tertentu (Suptanto, 2009:336).

\section{HASIL DAN PEMBAHASAN \\ Hasil Penelitian \\ Uji Normalitas}

Uji Normalitas digunakan untuk mengetahui apakah data yang diteliti untuk keseluruhan indikator tersebut bersifat normal. Uji Normalitas dapat dilakukan dengan analisis grafik, seperti gambar di bawah ini.

Gambar 2. Hasil Uji Normalitas

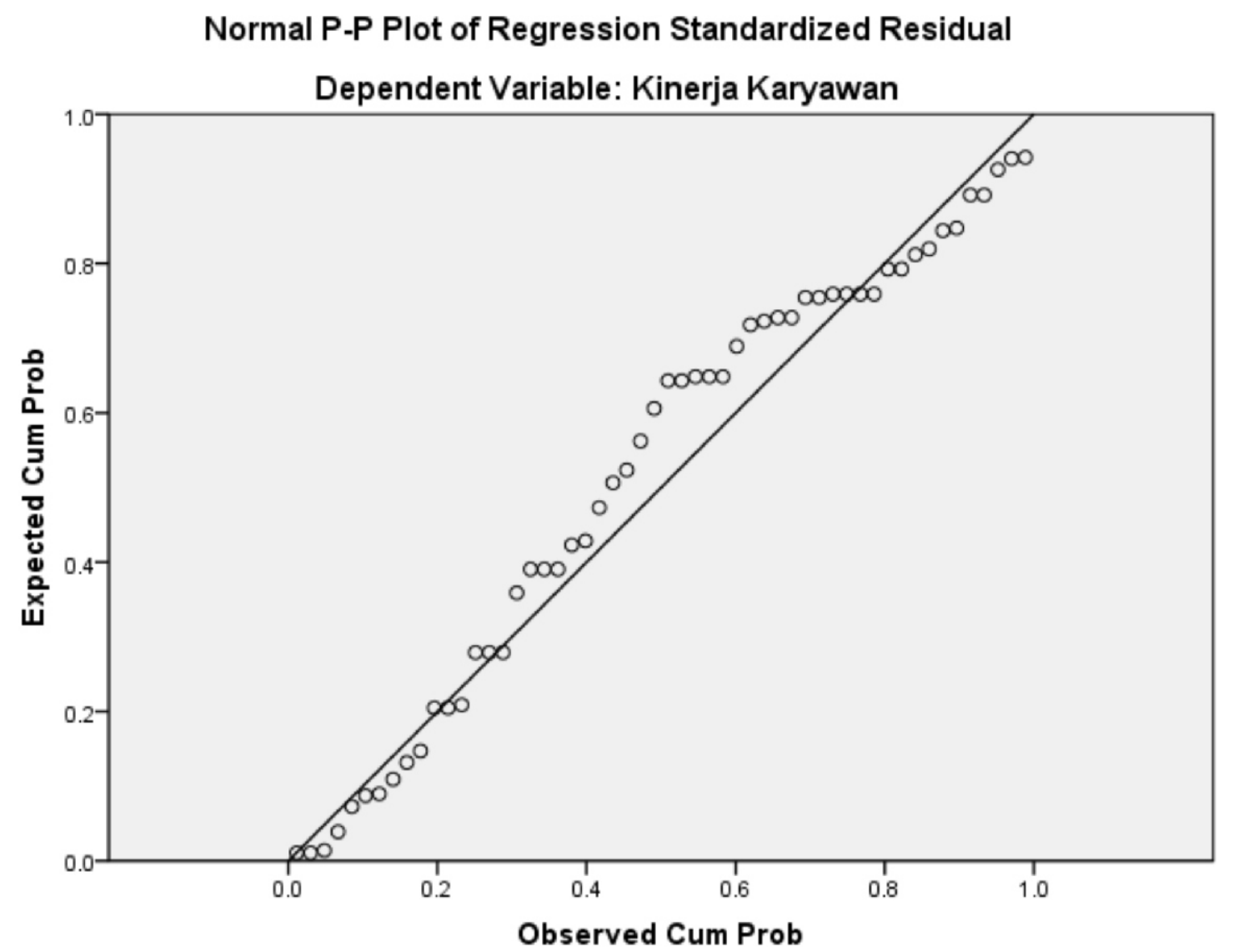

Sumber : Data Olahan SPSS 2019

Berdasarkan grafik Uji Normalitas di atas, dapat diketahui bahwa data menyebar di sekitar garis diagonal dan mengikuti arah garis diagonal. Ini menunjukkan distribusi data bersifat normal, sehingga asumsi untuk melakukan model regresi linier sederhana dapat dilakukan.

\section{Analisis Regresi Linear Sederhana}

Untuk melihat pengaruh variabel inde- penden yaitu Sistem Informasi Manajemen (variabel X) terhadap variabel dependen yaitu Kinerja Karyawan (variabel Y) serta memprediksi nilai variabel dependen dengan menggunakan variabel independen, digunakan analisis regresi sederhana. Untuk mendapatkan koefisien regresi (nilai a dan b), dicari menggunakan Software SPSS, hasil output SPSS sebagai berikut: 


\section{Tabel 6. Analisis Regresi}

Coefficients $^{\mathrm{a}}$

\begin{tabular}{|c|c|c|c|c|c|c|}
\hline & \multirow[t]{2}{*}{ Model } & \multicolumn{2}{|c|}{$\begin{array}{l}\text { Unstandardized } \\
\text { Coefficients }\end{array}$} & $\begin{array}{l}\text { Standardized } \\
\text { Coefficients }\end{array}$ & \multirow[b]{2}{*}{$\mathrm{t}$} & \multirow[b]{2}{*}{ Sig. } \\
\hline & & B & Std. Error & Beta & & \\
\hline \multirow[t]{2}{*}{1} & (Constant) & 25.788 & 6.700 & & 3.849 & .000 \\
\hline & $\begin{array}{l}\text { Sistem } \\
\text { Informasi } \\
\text { Manajemen }\end{array}$ & .652 & .161 & .489 & 4.048 & .000 \\
\hline
\end{tabular}

a. Dependent Variable: Kinerja Karyawan

Sumber : Data olahan SPSS 2019

Berdasarkan hasil output SPSS di atas, maka persamaan regresi yang terbentuk adalah:

$Y=25,788+0,652 X$

$\mathbf{Y}=\mathbf{a}+\mathbf{b X}$

\section{Keterangan:}

$\mathrm{Y}=$ Kinerja, yaitu subjek dalam variabel dependen (tidak bebas) yang diprediksikan.

$\mathrm{X}=$ Sistem Informasi Manajemen, yaitu subjek pada variabel independen (bebas) yang mempunyai nilai tertentu.

$\mathrm{a}=$ Parameter intercept

$\mathrm{b}=$ Parameter koefesien regresi variabel bebas

Dari model di atas dapat diketahui bahwa nilai dari a adalah 25,788 , nilai ini menunjukkan bahwa pada saat variabel Sistem Informasi Manajemen (variabel X) bernilai nol, maka Kinerja Karyawan (variabel Y) sebesar 25,788. Sedangkan nilai dari $b$ adalah 0,652 , artinya bahwa ketika terjadi peningkatan nilai variabel Sistem Informasi Manajemen (variabel X) sebesar 1 (satu) satuan, maka Kinerja Karyawan (variabel Y) maka meningkat sebesar 0,652 satuan.

\section{Uji Hipotesis}

Untuk mengetahui variabel bebas terhadap variabel terikat yang dilakukan pengujian hipotesis dengan menggunakan beberapa analisis statistik.

\section{Uji t}

\section{Tabel 7. Analisis Regresi}

\section{Coefficients $^{\mathrm{a}}$}

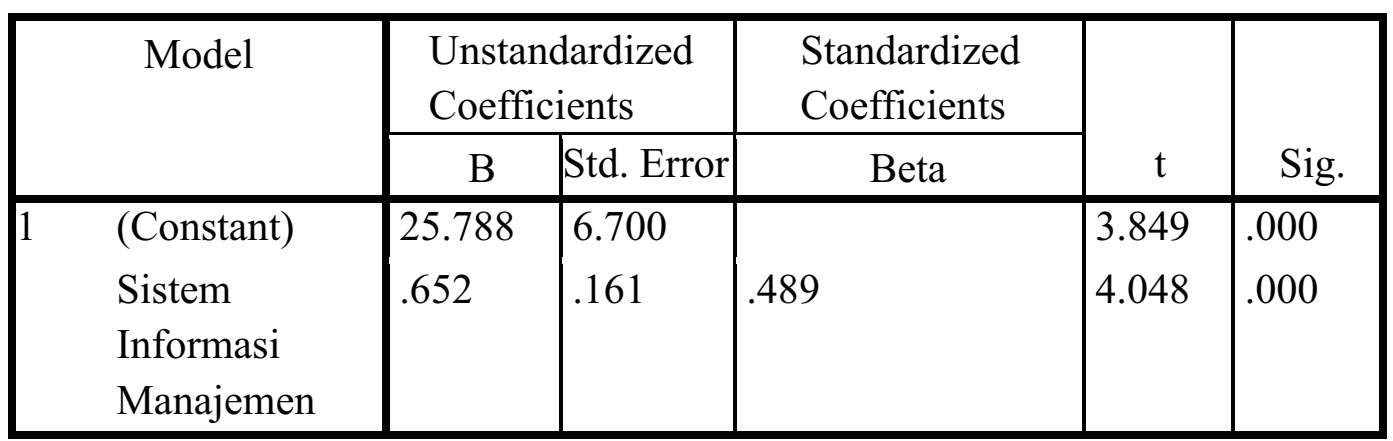

a. Dependent Variable: Kinerja Karyawan

Sumber : Data olahan SPSS 2019 
Berdasarkan pada tabel 5.30 di atas diperoleh nilai $\mathrm{t}$ hitung sebesar 4,048. Sedangkan nilai kritis menurut tabel dengan tingkat signifikan 5\% dengan menggunakan rumus $\mathrm{t}$ tabel $(\alpha / 2 ; \mathrm{n}-\mathrm{k}) \mathrm{k}=1$ dan $\mathrm{n}=54$ adalah 2.00575 , karena thitung $>$ t tabel maka H0 ditolak. Artinya terdapat pengaruh Sistem Informasi Manajemen terhadap Kinerja Karyawan. Dengan arti kata Hipotesis (Ha) diterima. Nilai t positif menunjukkan bahwa variabel Sistem Informasi Manajemen mempunyai hubungan yang searah dengan Kinerja Karyawan pada PT. Primanusa Globalindo Pekanbaru.

\section{Analisis Koefisien Determinasi}

Berdasarkan kontribusi variabel independen yaitu Sistem Informasi Manajemen (variabel X) terhadap variabel dependen yaitu Kinerja Karyawan (Variabel Y) dapat dihitung dengan mencari nilai koefisien determinasi. Dari hasil output SPSS didapatkan.

\section{Tabel 8. Analisis Determinasi}

\section{Model Summary}

\begin{tabular}{|l|l|r|r|r|}
\hline Model & $\mathrm{R}$ & R Square & $\begin{array}{c}\text { Adjusted R } \\
\text { Square }\end{array}$ & $\begin{array}{c}\text { Std. Error of } \\
\text { the Estimate }\end{array}$ \\
\hline 1 & $.489^{\mathrm{a}}$ & .240 & .225 & 3.104 \\
\hline
\end{tabular}

a. Predictors: (Constant), Sistem Informasi Manajemen

b. Dependent Variable: Kinerja Karyawan

Sumber : Data olahan SPSS 2019

Dari hasil tersebut didapatkan nilai koefisien determinasi ( $\mathrm{R}$ Square) sebesar 0,240 atau $24,0 \%$. Jadi dapat disimpulkan bahwa variabel Sistem Informasi Manajemen memberikan kontribusi terhadap perubahanperubahan variabel Kinerja Karyawan sebesar 24,0\%, sementara sisanya $76 \%$, dipengaruhi oleh faktor-faktor lainnya yang tidak diteliti dalam penelitian ini.

\section{PENUTUP}

\section{Simpulan}

Dari uraian yang penulis kemukakan pada bab-bab sebelumnya, maka penulis menarik beberapa kesimpulan antara lain:

1) Dari keseluruhan tanggapan responden terhadap variabel sistem informasi manajemen pada PT. Primanusa Globalindo Pekanbaru dengan skor rata-rata 4,61 menunjukkan tanggapan responden terhadap pernyataan pada variabel sistem informasi manajemen adalah sangat setuju. Dari keseluruhan tanggapan responden terhadap variabel kinerja karyawan pada PT. Primanusa Globalindo Pekanbaru dengan skor rata-rata 4,38 menunjukkan tanggapan responden terhadap pernyataan pada variabel kinerja karyawan adalah setuju.

2) Untuk melihat pengaruh variabel independen yaitu Sistem Informasi Manajemen (variabel X) terhadap variabel dependen yaitu Kinerja Karyawan (variabel Y). menggunakan analisis regresi sederhana dengan hasil $\mathrm{Y}=25,788+0,652 \mathrm{X}$ diketahui bahwa nilai dari a adalah 25,788, nilai ini menunjukkan bahwa pada saat variabel Sistem Informasi Manajemen (variabel $\mathrm{X})$ bernilai nol, maka Kinerja Karyawan (variabel Y) sebesar 25,788. Sedangkan nilai dari $b$ adalah 0,652 , artinya bahwa ketika terjadi peningkatan nilai variabel Sistem Informasi Manajemen (variabel 
X) sebesar 1 (satu) satuan, maka Kinerja Karyawan (variabel Y) maka meningkat sebesar 0,652 satuan.

3) Nilai t hitung sebesar 4,048 . Sedangkan nilai kritis menurut tabel dengan tingkat signifikan 5\% dengan menggunakan rumus $\mathrm{t}$ tabel $(\alpha / 2 ; \mathrm{n}-\mathrm{k}) \mathrm{k}=1$ dan $\mathrm{n}=54$ adalah 2.00575, karena thitung $>\mathrm{t}$ tabel maka H0 ditolak. Artinya terdapat pengaruh Sistem Informasi Manajemen terhadap Kinerja Karyawan. Dengan arti kata Hipotesis (Ha) diterima. Nilai $\mathrm{t}$ positif menunjukkan bahwa variabel Sistem Informasi Manajemen mempunyai hubungan yang searah dengan Kinerja Karyawan pada PT. Primanusa Globalindo Pekanbaru.

4) Sistem informasi manajemen mempunyai hubungan yang searah dengan kinerja karyawan pada PT. Primanusa Globalindo Pekanbaru. Nilai koefisien determinasi (R Square) sebesar 0,240 atau 24,0\%. Jadi dapat disimpulkan bahwa variabel Sistem Informasi Manajemen memberikan kontribusi terhadap perubahan-perubahan variabel Kinerja Karyawan sebesar $24,0 \%$, sementara sisanya $76 \%$, dipengaruhi oleh faktor-faktor lainnya yang tidak diteliti dalam penelitian ini.

\section{Saran}

Berdasarkan simpulan di atas, maka dapat diberikan saran sebagai berikut:

1. Untuk peningkatan sistem informasi manajemen yang nantinya akan berpengaruh terhadap kinerja karyawan maka sebaiknya dalam memberikan pelatihan kepada karyawan PT. Primanusa Globalindo Pekanbaru dapat meningkatkan kinerjanya dalam bekerja.

2. Kinerja karyawan pada PT. Primanusa Globalindo Pekanbaru berada pada kategori setuju. Perlu diperhatikan hal-hal yang memberikan kontribusi terhadap peningkatan kinerja karyawan. Untuk peningkatan kinerja karyawan sebaiknya dapat diberikan pelatihan secara berulang agar karyawan dapat meningkatkan kinerjanya dalam bekerja.

3. Harapan penulis Skripsi ini dapat dijadikan referensi untuk penelitian selanjutnya dengan judul yang sama dan disarankan untuk lebih mendalami dan melanjutkan penulisan ini agar bisa bermanfaat untuk orang banyak.

\section{DAFTAR PUSTAKA}

Adhityo Kuncoro. (2017). Korelasi Penguasaan Kosakata Dengan Keterampilan Berbicara Siswa Dalam Bahasa Inggris. Jurnal Ilmiah Teknik Informatika Universitas Indraprasta PGRI, Volume 1, Nomor 3, Edisi April.

Alwan, Menza Hendri, Darmaji. (2017). Faktor-Faktor Yang Mendorong Siswa MIA SMAN Mengikuti Bimbingan Belajar Luar Sekolah Di Kecamatan Telanaipura Kota Jambi. Jurnal Ilmiah Fisika FKIP Universitas Jambi. Volume 2, Nomor 1, Edisi Juli.

Anggadini, Sri Dewi. (2013). Analisis Sistem Informasi Manajemen Berbasis Komputer dalam Proses Pengambilan Keputusan. Jurnal Majalah Ilmiah UNIKOM. Volume 11, Nomor 2.

Arikunto, Suharsimi. (2010). Prosedur Penelitian Suatu Pendekatan Praktis. Rineka Cipta, Jakarta.

Edhy, Susanta. (2003). Sistem Informasi Manajemen. Graha Ilmu, Yogyakarta.

Edi Saputra Pakpahan, Siswidiyanto, Sukanto. (2014). Pengaruh Pendidikan Dan Pelatihan Terhadap Kinerja Pegawai. Jurnal Ilmiah Administrasi Publik, Universitas Brawijaya Malang. Volume 2, Nomor 1. 
Susanto, Azhar. (2000). Sistem Informasi Manajemen Konsep dan Pengembangannya. Lingga Jaya. Bandung.

Hakim, Wuryanto. (2014). Model Peningkatan Kinerja Karyawan Melalui Peran Komunikasi dan Motivasi serta Pengaruhnya Terhadap Kepuasan Kerja. Jurnal EKOBIS, volume 15, nomor 2.

Hasibuan, S.P., Melayu. (2000). Manajemen Sumberdaya Manusia. Bumi Aksara, Jakarta.

J. Supranto. (2009). Statistik Teori dan Aplikasi. Edisi ketujuh Jilid 2, Erlangga: Jakarta.

Jogiyanto. (2005). Analisis \& Desain Sistem Informasi Pendekatan Terstruktur Teori dan Praktek Aplikasi Bisnis. Andi, Yogyakarta.

Khamiyati. (2017). Evaluasi Persiapan Perpustakaan STIKES 'Aisyiyah Yogyakarta dalam Membangun Perpustakaan Digital. Jurnal Ilmiah UNISA Yogyakarta. Edisi Juni.

Kristianto, Wheny, dkk. (2015). Sistem Informasi Manajemen, UNEJ, Jember.

Makmur, Syarif. (2007). Pemberdaya Sumber Daya Manusia dan Efektivitas Organisasi, Rajawali Pers: Jakarta.

Mangkunegara A., A. Anwar Prabu, (2007). Manajemen Sumber Daya Manusia Perusahaan. Cetakan Pertama. Remaja Rosda Karya: Bandung.

Manajemen Sumber Daya Manusia. PT. Gomaja Rosda Karya: Bandung.

Nurmansyah. (2018). Sistem Informasi Manajemen. Unilak Press, Pekanbaru.

Rizky Primadita, Ayuwardani. (2018). Pengaruh Informasi Keuangan Dan Non Keuangan Terhadap Underprocing
Harga Saham Pada Perusahaan Yang Melakukan Initial Public. Jurnal Nominal Pendidikan Akuntansi, Universitas Negeri Yogyakarta, volume VII, Nomor 1.

Prasojo, Lantip Diat. (2013). Sistem Informasi Manajemen. UNY Press: Yogyakarta.

Rusdiana, Moch. Irfan. (2014). Sistem Informasi Manajemen. Pustaka Setia: Bandung.

Sidh, Rahmawati. (2013). Peranan Brainware dalam Sistem Informasi Manajemen. Jurnal Computech \& Bisnis, volume 7 , nomor 1, (19-29).

Sirait, Ganda. (2014). Pengaruh Sistem Informasi Manajemen Terhadap Efektivitas Kerja Pegawai Pada Hollan Bakery Batam. Jurnal Ilmiah Manajemen Universitas Putera Bata, volume 2, nomor 2, Edisi Juli.

Sujarweni, Wiratna. (2014). Metodologi Penelitian : Lengkap, Praktis, dan Mudah Dipahami. Yogyakarta: PT. Pustaka Baru.

Sugiyono. (2003). Metodelogi Penelitian Bisnis. Alfabeta, Bandung.

Susanto, Azhar. (2000). Sistem Informasi Manajemen Konsep dan Pengembangannya. Lingga Jaya: Bandung.

( $\left.\begin{array}{llll}2 & 0 & 1 & 7\end{array}\right)$.

Sistem Informasi Manajemen. Lingga Jaya: Bandung.

Suyitno. (2017). Analisis Penerapan Sistem Informasi Manajemen dan Kompetensi Pegawai Serta Pengaruhnya Terhadap Kinerja Pegawai. Jurnal Ilmiah Business Administration, Sekolah Tinggi Ilmu Ekonomi (STIE) Indonesia Malang, volume 1, nomor 2, Edisi September. 